\title{
Self-reported knowledge and awareness
}

\section{about blood pressure and hypertension:}

\section{a cross-sectional study of a random sample of men and women aged $60-74$ years}

\author{
This article was published in the following Dove Press journal: \\ Clinical Epidemiology \\ 15 February 2014 \\ Number of times this article has been viewed
}

\author{
Ina Qvist' \\ Marie D Thomsen ${ }^{2}$ \\ Jes S Lindholt ${ }^{2,3}$ \\ Hans Ibsen ${ }^{4}$ \\ Jeroen ML Hendriks ${ }^{5}$ \\ Lars Frost ${ }^{\prime}$ \\ 'Department of Medicine, Diagnostic \\ Centre, University Research Clinic \\ for Innovative Patient Pathways, \\ Silkeborg Regional Hospital, Silkeborg, \\ Denmark; ${ }^{2}$ Department of Vascular \\ Surgery, Viborg Regional Hospital \\ and Institute of Clinical Medicine, \\ Aarhus University Hospital, Aarhus, \\ Denmark; ${ }^{3}$ Centre of Individualized \\ Medicine in Arterial Diseases, \\ Department of Cardiothoracic and \\ Vascular Department T, Odense \\ University Hospital, Odense, \\ Denmark; ${ }^{4}$ Department of Medicine, \\ Holbæk Hospital, Holbæk, Denmark; \\ ${ }^{5}$ Department of Cardiology, \\ Maastricht University Medical Centre, \\ Maastricht, the Netherlands
}

Background: In general, it is assumed that patient education, by increasing knowledge, may change behavior and lifestyle and promote health. In this context, it is a surprise that knowledge and awareness about blood pressure and hypertension among elderly people is poor. We hypothesized that knowledge about blood pressure and hypertension would be better among individuals with self-reported hypertension compared with subjects without self-reported hypertension.

Methods: We mailed a questionnaire to a random sample of 1,000 subjects living in the municipality of Silkeborg, Denmark. The study sample was drawn from the Central Person Registry.

Results: The response rate was $72 \%$. Of these, $43 \%$ of responders had self-reported hypertension. The people with self-reported hypertension were older, less educated, had higher self-reported blood cholesterol levels, had higher body weight, and more often had a family history of hypertension. More than $80 \%$ reported that overweight and obesity increases blood pressure. More than $60 \%$ reported that untreated hypertension may cause heart disease or stroke. More than half of the responders did not know their blood pressure, and only $21 \%$ knew that hypertension can occur without symptoms. Knowledge about hypertension was independent of self-reported hypertension status, but awareness about blood pressure was most prominent among those with self-reported hypertension.

Conclusion: General knowledge about blood pressure and hypertension was reasonable, but there is still room for improvement in elderly people's knowledge and awareness of blood pressure.

Keywords: self-reported hypertension, questionnaire, elderly, blood pressure

\section{Introduction}

Primary prevention of heart disease and health promotion has been in focus for decades. Health care in the primary and secondary care sector has evolved to strengthen the citizen's opportunities to engage in prevention and health promotion. ${ }^{1}$ Half of patients with hypertension are unaware of their condition. ${ }^{2-7}$ The prevalence of hypertension in the adult Danish population is estimated to be $22.3 \%$. The prevalence spans from $1 \%$ in those aged $20-29$ years to $69 \%$ among those aged $80-89$ years. ${ }^{8}$ Among Danish patients with known hypertension, only $40 \%-50 \%$ are treated to the guideline recommended blood pressure of less than $140 / 90 \mathrm{~mm} \mathrm{Hg}^{7-9}$ The situation is far worse in less-developed countries. For patients with coronary heart disease or stroke, the use of blood pressure-lowering drugs decreases from $69 \%$ in high-income countries to $16 \%$ in low-income countries. ${ }^{10}$ There is a genetic
Correspondence: Ina Qvist

Department of Medicine MI,

Diagnostic Centre, Silkeborg Hospital,

Falkevej I-3, 8600 Silkeborg, Denmark

Email inaqvist@rm.dk 
predisposition for hypertension, and men develop hypertension earlier than women. Obesity, ${ }^{11,12}$ high salt intake, ${ }^{13,14}$ physical inactivity, ${ }^{15,16}$ and excess alcohol consumption ${ }^{17}$ increase the risk of hypertension. Proven interventions to prevent the development of hypertension include reduction of weight and alcohol intake; increase in leisure time exercise; healthy diet, with low saturated fat; and reduced salt intake. ${ }^{11,12,15-20}$

Health campaigns have been addressed to entire populations, but a systematic patient education program for hypertensive patients does not exist. In this context, it is surprising that there is little information about elderly people's knowledge and awareness of their blood pressure.

In this study we examined self-reported hypertension knowledge in a population-based random sample of people aged 60-74 years. We hypothesized that knowledge and awareness about blood pressure would be better among individuals with self-reported hypertension compared with subjects without self-reported hypertension. Individuals with "self-reported hypertension" were defined as those who reported use of antihypertensive drugs.

\section{Study population and methods Source population}

The source population consisted of 6,803 men and 6,923 women aged 60-74 years who were living in the municipality of Silkeborg, Denmark. In the year 2010, the population of the municipality of Silkeborg comprised 42,396 inhabitants. The mean income per inhabitant in the municipality of Silkeborg was DKK 282,000 vs DKK 283,000 in the general Danish population. The employment rate in the municipality of Silkeborg was $74.9 \%$ vs $72.2 \%$ in the general Danish population. The sample population was randomly drawn from the Central Person Registry of Denmark by the research department at the Danish Health and Medicines Authority. The age interval of 60-74 years was chosen because of a high prevalence of hypertension in this age group. To increase the internal validity of our study, we did not include subjects older than 74 years because we anticipated a low response rate among people older than 75 years.

The study was approved by the Danish Data Protection Agency. There was no requirement for approval from an ethical committee because the responses from the participants were anonymous.

\section{The questionnaire}

The questionnaire was developed by the investigator in cooperation with nurses and doctors working in cardiology wards, dialysis units, outpatient clinics, and general practices, based on relevant and useful questions that emerged from the literature $^{21}$ and clinical experience.

The questionnaire asked for information on sex, age, civil status, number of children, and education. There were additional questions about height, weight, cholesterol, and hypertension risk factors. The questions on the knowledge of hypertension symptoms were in multiple-choice format and focused on the following areas: a) factors that influence blood pressure, b) the symptoms of hypertension, c) the consequences of hypertension, and d) awareness of one's own blood pressure.

The questionnaire was tested in a pilot study of 31 subjects aged 60-74 years and adjusted accordingly. The questionnaire was then mailed to the study population, together with a letter explaining the purpose of the study. We did not validate the questionnaire by repeating it because we assumed participants might seek information between examinations.

\section{Statistics}

We used the two-sample Student's $t$-test, chi-square test, and Wilcoxon rank sum test, where appropriate. Odds ratios (ORs) were calculated with 95\% confidence intervals (CIs). We used STATA 9 statistical software (StataCorp, College Station, TX, USA).

\section{Results}

The sample population consisted of 493 men and 507 women. Of those, 727 subjects responded. Seven of the returned questionnaires were excluded because they were received after the response deadline. Two respondents were excluded due to missing data. Thus, the final study population (ie, the responders) consisted of 718 subjects, which corresponds to a $72 \%$ response rate.

Table 1 shows characteristics of the responders and nonresponders. These two groups were comparable with respect to sex and age, but fewer of those living alone responded (OR=0.38 [95\% CI: 0.28-0.52]).

Table 2 shows the demographic, social, anthropometric, and self-assessed general health characteristics, in participants with and without self-reported hypertension. A total of 307 participants $(43 \%)$ reported having hypertension, and $411(57 \%)$ reported not having hypertension. Those with self-reported hypertension were more often men, were older, were overweight or obese, and had a lower educational level. Those with self-reported hypertension more often had a family history of hypertension, increased cholesterol levels, and a lower self-estimated general health condition than did those with no self-reported hypertension. 
Table I Characteristics of the responders and nonresponders

\begin{tabular}{|c|c|c|c|c|}
\hline & $\begin{array}{l}\text { Responders } \\
\text { N (\%) }\end{array}$ & $\begin{array}{l}\text { Nonresponders } \\
\text { N (\%) }\end{array}$ & $\begin{array}{l}\text { Odds ratio } \\
(95 \% \mathrm{Cl})\end{array}$ & $P$-value \\
\hline Sex & & & & 0.57 \\
\hline Men & $358(50.6)$ & 135 (47.9) & Reference & \\
\hline Women & $360(49.4)$ & 147 (52.1) & $0.92(0.69-1.23)$ & \\
\hline Age (mean \pm SD) & $66.6 \pm 4.2$ & $66.7 \pm 4.2$ & & 0.735 \\
\hline Men & $66.6 \pm 4.2$ & $66.8 \pm 4.3$ & & 0.640 \\
\hline Women & $66.6 \pm 4.1$ & $66.7 \pm 4.2$ & & 0.580 \\
\hline Civil status & & & & $<0.001$ \\
\hline Living with a partner & $575(80.1)$ & I7I (60.6) & Reference & \\
\hline Living alone & 143 (19.9) & III (39.4) & $0.38(0.28-0.52)$ & \\
\hline Men & & & & $<0.001$ \\
\hline Living with a partner & $312(87.2)$ & 97 (7I.9) & Reference & \\
\hline Living alone & $46(12.8)$ & $38(28.1)$ & $0.38(0.23-0.63)$ & \\
\hline Women & & & & $<0.001$ \\
\hline Living with a partner & $263(73.1)$ & $74(50.3)$ & Reference & \\
\hline Living alone & $97(26.9)$ & $73(49.7)$ & $0.37(0.25-0.57)$ & \\
\hline
\end{tabular}

Abbreviations: $\mathrm{Cl}$, confidence interval; SD, standard deviation.

Table 2 Demographic, social, anthropometric, and self-assessed general health characteristics in subjects with and without selfreported hypertension

\begin{tabular}{|c|c|c|c|c|}
\hline Variable & $\begin{array}{l}\text { Self-reported hypertension } \\
\text { Mean } \pm \text { SD/N (\%) }\end{array}$ & $\begin{array}{l}\text { No self-reported hypertension } \\
\text { Mean } \pm \text { SD/N (\%) }\end{array}$ & $\begin{array}{l}\text { Odds ratio } \\
(95 \% \mathrm{Cl})\end{array}$ & $P$-value \\
\hline Number & $307(42.8)$ & $4 I I(57.2)$ & & \\
\hline Age & $66.9 \pm 4.3$ & $65.6 \pm 4.0$ & & $<0.001$ \\
\hline Sex & & & & 0.072 \\
\hline Men & $165(53.8)$ & $193(47.0)$ & Reference & \\
\hline Women & $142(46.2)$ & $218(53.0)$ & $0.76(0.57-1.02)$ & \\
\hline Civil status & & & & 0.686 \\
\hline Living with a partner & $248(80.8)$ & $327(79.6)$ & Reference & \\
\hline Living alone & $59(19.2)$ & $84(20.4)$ & $0.93(0.64-1.34)$ & \\
\hline Children & & & & 0.642 \\
\hline Yes & $277(90.2)$ & $375(91.2)$ & Reference & \\
\hline No & $30(9.8)$ & $36(8.8)$ & $1.13(0.68-1.88)$ & \\
\hline Education & & & & 0.005 \\
\hline Higher education, more than 4 years & $13(4.2)$ & $26(6.3)$ & & \\
\hline Higher education, 3-4 years & $53(17.2)$ & $89(21.6)$ & & \\
\hline Higher education, less than 3 years & $29(9.5)$ & $52(12.7)$ & & \\
\hline Skilled training & I $32(43.0)$ & I6I (39.2) & & \\
\hline Basic schooling + short supplement & $29(9.5)$ & $39(9.5)$ & & \\
\hline Basic schooling & $51(16.6)$ & $44(10.7)$ & & \\
\hline Height $(\mathrm{cm})$ & $171.3 \pm 7.9$ & $171.0 \pm 8.5$ & & 0.671 \\
\hline Weight (kg) & $79.3 \pm 15.2$ & $73.2 \pm 13.6$ & & $<0.001$ \\
\hline BMI $\left(\mathrm{kg} \mathrm{m}^{2}\right)$ & $27.0 \pm 4.6$ & $24.9 \pm 3.9$ & & $<0.001$ \\
\hline Self-reported high cholesterol level & & & & $<0.001$ \\
\hline No & III (36.I) & $195(47.4)$ & Reference & \\
\hline Yes & $170(55.4)$ & $133(32.4)$ & $2.25(1.62-3.11)$ & \\
\hline Do not know & $26(8.5)$ & $83(20.2)$ & $0.55(0.33-0.91)$ & \\
\hline Self-reported family history of hypertension & & & & $<0.001$ \\
\hline No & $26(8.5)$ & $124(30.2)$ & Reference & \\
\hline Yes & $130(42.3)$ & $109(26.5)$ & $5.69(3.47-9.32)$ & \\
\hline Do not know & I5I (49.2) & $178(43.3)$ & $4.05(2.52-6,51)$ & \\
\hline Self-reported general health condition & & & & $<0.001$ \\
\hline Excellent & $18(5.9)$ & $53(12.9)$ & & \\
\hline Good & $149(48.5)$ & $238(57.9)$ & & \\
\hline Fair & $123(40.1)$ & $103(25.1)$ & & \\
\hline $\mathrm{Bad}$ & $14(4.5)$ & $14(3.4)$ & & \\
\hline Very bad & $3(1.0)$ & $3(0.7)$ & & \\
\hline
\end{tabular}

Abbreviations: $\mathrm{Cl}$, confidence interval; SD, standard deviation; BMI, body mass index. 
In general, knowledge about the lifestyle factors that may influence blood pressure was good, irrespective of the self-reported hypertension status (Table 3). More than $80 \%$ of the respondents reported that blood pressure is influenced by stress and obesity.

Table 3 shows the knowledge about hypertension symptoms, according to the self-reported hypertension status. In general, the knowledge about hypertension symptoms was sparse. For example, less than one-third reported that hypertension may not cause symptoms, and a minority knew that hypertension may cause nosebleeds. There were no systematic differences between the groups, although more people with self-reported hypertension knew that hypertension may not cause symptoms, and more people without self-reported hypertension knew that hypertension may cause headache and palpitations.

The knowledge about complications related to hypertension was good, irrespective of the self-reported hypertension status (Table 4). Eight out of ten subjects reported that hypertension may cause stroke.

Table 5 shows the data on the awareness of blood pressure and blood pressure control, according to the self-reported blood pressure status. A total of $81 \%$ of those with selfreported hypertension reported that they knew their blood pressure value, while $55 \%$ of those without self-reported hypertension knew their blood pressure (OR=3.51 [95\% CI: 2.46-5.04]). More subjects with self-reported hypertension planned to have their blood pressure measured within one year $(\mathrm{OR}=5.0$ [95\% CI: 2.47-10.0]).

\section{Discussion}

\section{Comparison with prior literature}

Our finding of an association between age, weight, selfreported cholesterol level, a family history of hypertension, education level, and self-reported hypertension is in concordance with previous findings. ${ }^{22-24}$ In comparison with our study, a survey in the USA among people older than 65 years found a similar knowledge about the lifestyle factors that may influence blood pressure but a higher prevalence of knowledge about the complications of untreated high blood pressure. ${ }^{25} \mathrm{~A}$ survey in Canada among people older than 40 years found a limited knowledge of the lifestyle issues affecting hypertension and a poor understanding of the consequences of high blood pressure or hypertension. The Canadian study also showed that two-thirds of the respondents thought hypertension had clearly identifiable signs or symptoms. ${ }^{26}$ We found that only $20 \%$ knew that hypertension can occur without symptoms, which is in line with the results of a study from Austria, among a sample aged 15 years and older. ${ }^{27}$

It was not surprising that people with self-reported hypertension had better blood pressure-related knowledge because they are assumed to have blood pressure measured more frequently and to have more frequent contact with health care services. On the other hand they did not have more knowledge regarding lifestyle influences on blood pressure than those without self-reported hypertension. This finding could be explained by the fact that hypertensive patients were older and less educated. This accords with the Euroaspire III

Table 3 Knowledge about factors that may influence blood pressure and knowledge about symptoms of hypertension, according to self-reported hypertension status

\begin{tabular}{|c|c|c|c|c|c|}
\hline & \multicolumn{2}{|c|}{ Self-reported hypertension } & \multicolumn{2}{|c|}{ No self-reported hypertension } & \multirow{2}{*}{$\begin{array}{l}\text { Odds ratio } \\
(95 \% \mathrm{Cl})\end{array}$} \\
\hline & $\begin{array}{l}\text { Yes } \\
\text { N (\%) }\end{array}$ & $\begin{array}{l}\text { No } \\
\text { N (\%) }\end{array}$ & $\begin{array}{l}\text { Yes } \\
\text { N (\%) }\end{array}$ & $\begin{array}{l}\text { No } \\
\text { N (\%) }\end{array}$ & \\
\hline \multicolumn{6}{|c|}{ Do you think your blood pressure is affected either positively or negatively by? } \\
\hline Alcohol & $173(56.4)$ & $134(43.6)$ & $233(56.7)$ & $178(43.3)$ & $0.98(0.72-1.34)$ \\
\hline Smoking & $216(70.4)$ & $91(29.6)$ & $311(75.7)$ & $100(24.3)$ & $0.76(0.54-1.08)$ \\
\hline Exercise & $173(56.4)$ & $134(43.6)$ & $240(58.4)$ & $|7|(4 \mid .6)$ & $0.91(0.67-1.25)$ \\
\hline Obesity & $256(83.4)$ & $51(16.6)$ & $352(85.6)$ & $59(14.4)$ & $0.84(0.55-1.29)$ \\
\hline Stress & $249(81.1)$ & $58(18.9)$ & $334(8 \mid .3)$ & 77 (18.7) & $0.99(0.67-1.47)$ \\
\hline Other & $6(1.9)$ & $301(98.1)$ & $6(1.5)$ & $405(98.5)$ & $1.35(0.36-5.08)$ \\
\hline \multicolumn{6}{|c|}{ What kinds of symptoms are seen in high blood pressure? } \\
\hline None & $92(30.0)$ & $215(70.0)$ & $87(2 \mid .2)$ & $324(78.8)$ & $1.59(1.12-2.27)$ \\
\hline Headache & $156(50.8)$ & $|5|(49.2)$ & $257(62.5)$ & $154(37.5)$ & $0.62(0.45-0.85)$ \\
\hline Nosebleeds & $68(22.1)$ & $239(77.9)$ & $95(23.1)$ & $316(76.9)$ & $0.95(0.65-1.37)$ \\
\hline Palpitations & I2I (39.4) & $186(60.6)$ & $207(50.4)$ & $204(49.6)$ & $0.64(0.47-0.87)$ \\
\hline Shortness of breath & $101(32.9)$ & $206(67.1)$ & $154(37.5)$ & $257(62.5)$ & $0.82(0.59-1.29)$ \\
\hline Other & II (3.5) & $296(96.5)$ & $6(1.5)$ & $405(98.5)$ & $2.5 \mathrm{I}(0.84-8.34)$ \\
\hline
\end{tabular}

Abbreviation: $\mathrm{Cl}$, confidence interval. 
Table 4 Knowledge of hypertension complications, according to self-reported hypertension status

\begin{tabular}{|c|c|c|c|c|c|}
\hline & \multicolumn{2}{|c|}{ Self-reported hypertension } & \multicolumn{2}{|c|}{ No self-reported hypertension } & \multirow{3}{*}{$\begin{array}{l}\text { Odds ratio } \\
(95 \% \mathrm{Cl})\end{array}$} \\
\hline & Yes & No & Yes & No & \\
\hline & $\mathbf{N}(\%)$ & $\mathbf{N}(\%)$ & $\mathbf{N}(\%)$ & $\mathbf{N}(\%)$ & \\
\hline \multicolumn{6}{|c|}{ Can high blood pressure cause? } \\
\hline Heart disease* & $212(69.1)$ & $95(30.9)$ & $256(62.3)$ & $155(37.7)$ & $1.35(0.97-1.87)$ \\
\hline Cancer & $2(0.7)$ & $305(99.3)$ & $\mathrm{I}(0.2)$ & $10(99.8)$ & \\
\hline Myocardial infarction* & $252(82.1)$ & $55(17.9)$ & $327(79.6)$ & $84(20.4)$ & $\mathrm{I} .78(0.79-\mathrm{I} .75)$ \\
\hline Osteoarthritis & $9(2.9)$ & $298(97.1)$ & $3(0.7)$ & $408(99.3)$ & \\
\hline Diabetes & $52(16.9)$ & $255(83.1)$ & $57(13.9)$ & $354(86.1)$ & \\
\hline Atherosclerosis* & $126(4 \mid .0)$ & $|8|(59.0)$ & $162(39.4)$ & $249(60.6)$ & $1.07(0.78-1.45)$ \\
\hline Renal disease* & $51(16.6)$ & $256(83.4)$ & $51(12.4)$ & $360(87.6)$ & $1.41(0.90-2.18)$ \\
\hline Stroke* & $237(77.2)$ & $70(22.8)$ & $332(80.8)$ & $79(19.2)$ & $0.80(0.55-1.18)$ \\
\hline Pulmonary disease & $9(2.9)$ & $298(97.1)$ & $15(3.6)$ & $396(96.4)$ & \\
\hline Allergy & I $(0.3)$ & $306(99.7)$ & $3(0.7)$ & $408(99.3)$ & \\
\hline Impaired vision* & $88(28.7)$ & $219(71.3)$ & $107(26.0)$ & $304(74.0)$ & $1.10(0.8 \mathrm{I}-\mathrm{I} .6 \mathrm{I})$ \\
\hline Thyrotoxicosis & $18(5.9)$ & $289(94.1)$ & $35(8.5)$ & $376(91.5)$ & \\
\hline Liver disease & $12(3.9)$ & $295(96.1)$ & $9(2.2)$ & $402(97.8)$ & \\
\hline
\end{tabular}

Note: *Complication of hypertension.

Abbreviation: $\mathrm{Cl}$, confidence interval.

survey, which documented that patients with coronary heart disease and obesity, diabetes, or dyslipidemia need better management and control of their hypertension. ${ }^{28}$

\section{Strengths and weaknesses}

The study sample was drawn randomly and restricted to elderly people, a population with a high prevalence of hypertension. The response rate was good, making the risk of nongeneralizability of study results low. Our study findings may well be extended to the general Danish population because the population of the municipality of Silkeborg shares income and employment rate characteristics with the general Danish population. The study is unique because it was specifically designed for a population with a high prevalence of hypertension, in contrast to other studies that were aimed at the general public. $2,3,5,7,26,27$ The multiple choice questionnaire was adjusted after a pilot study. Only a few questionnaires had missing data.

Among those who did not respond, the majority of people were living alone. It may be that the lack of support from a partner contributed to nonresponse. Less knowledge of the subject may also be a reason why almost $28 \%$ did not answer the questionnaire. It was not possible to examine for potential selection bias by education and income levels. However, it is well known that participation rates are lower among deprived people. ${ }^{29}$ We consider it very likely that those with self-reported hypertension did indeed have hypertension. In cases of self-reported hypertension, part of the questionnaire would have been impossible to fill out if there was no use of antihypertensive drugs or contact with the health care system.

Some of the participants without self-reported hypertension may have had hypertension.

In this age group it is likely that about $40 \%-50 \%$ of those who are unaware of their blood pressure do have high blood pressure. ${ }^{2,3,5-7}$ Studies that use self-reported hypertension underestimate the true prevalence of hypertension. ${ }^{30,31}$ We did not include questions on the effect of salt on blood pressure because a reduction in population intake of salt primarily is a public health issue that involves governments, regulatory authorities and the food industry. ${ }^{32}$

The diagnosis and management of hypertension can be improved by opportunistic screening for hypertension, together

Table 5 Awareness of own blood pressure and blood pressure control, according to self-reported blood pressure status

\begin{tabular}{|c|c|c|c|c|c|}
\hline & \multicolumn{2}{|c|}{ Self-reported hypertension } & \multicolumn{2}{|c|}{ No self-reported hypertension } & \multirow{2}{*}{$\begin{array}{l}\text { Odds ratio } \\
(95 \% \mathrm{Cl})\end{array}$} \\
\hline & & $\mathbf{N}(\%)$ & & $\mathbf{N}(\%)$ & \\
\hline Do you know the result of your & No & $59(19.2)$ & No & $187(45.5)$ & Reference \\
\hline latest blood pressure measurement? & Yes & $248(80.8)$ & Yes & $224(54.5)$ & $3.51(2.46-5.04)$ \\
\hline Do you plan to have your blood pressure & No & $10(3.3)$ & No & $49(11.9)$ & Reference \\
\hline \multirow[t]{2}{*}{ measured within the next year? } & Yes & $287(93.5)$ & Yes & $283(68.9)$ & $5.00(2.47-10.0)$ \\
\hline & Do not know & $10(3.3)$ & Do not know & $79(19.2)$ & $0.62(0.24-1.60)$ \\
\hline
\end{tabular}

Abbreviation: $\mathrm{Cl}$, confidence interval. 
with complex interventions in the health care system to support health care for those with hypertension. In that respect nurseled clinics have been recommended in the management of hypertension ${ }^{33}$ and promising results have been reported. ${ }^{34}$

Finally, the multiple choice format of the questionnaire is likely to cause "false positive" responses. This may have caused us to overestimate the knowledge about hypertension.

\section{Future research}

Much more knowledge about the efficacy of patienteducation strategies need to be gained to improve general knowledge, behavior, lifestyle and hopefully prognosis related to hypertension.

\section{Conclusion}

The knowledge about blood pressure and hypertension was reasonable in general. However, nearly half of the study population without self-reported hypertension was unaware of their blood pressure, and $80 \%$ of the respondents did not know that hypertension can occur without symptoms. There is still room for improvement in elderly people's knowledge and awareness about blood pressure.

\section{Acknowledgments}

We thank Leif Spange Mortensen, MSc, of the UNI-C, The Danish Information Technology Centre for Education and Research, Aarhus, Denmark, for helpful comments in relation to the statistical analyses.

The study was supported in part, by a grant from the Research Foundation at Silkeborg Hospital.

\section{Disclosure}

The authors report no conflicts of interest in this work.

\section{References}

1. Graham I, Atar D, Borch-Johnsen K, et al; European Society of Cardiology (ESC) Committee for Practice Guidelines (CPG). European guidelines on cardiovascular disease prevention in clinical practice: executive summary: Fourth Joint Task Force of the European Society of Cardiology and Other Societies on Cardiovascular Disease Prevention in Clinical Practice (Constituted by representatives of nine societies and by invited experts). Eur Heart J. 2007;28(19):2375-2414.

2. Centers for Disease Control and Prevention (CDC). Vital signs: awareness and treatment of uncontrolled hypertension among adults - United States, 2003-2010. MMWR Morb Mortal Wkly Rep. 2012;61:703-709.

3. Carrington MJ, Jennings GL, Stewart S. Pattern of blood pressure in Australian adults: results from a national blood pressure screening day of 13,825 adults. Int $J$ Cardiol. 2010;145(3):461-467.

4. Cutler JA, Sorlie PD, Wolz M, Thom T, Fields LE, Roccella EJ. Trends in hypertension prevalence, awareness, treatment, and control rates in United States adults between 1988-1994 and 1999-2004. Hypertension. 2008;52(5):818-827.
5. Gee ME, Bienek A, McAlister FA, et al. Factors associated with lack of awareness and uncontrolled high blood pressure among Canadian adults with hypertension. Can J Cardiol. 2012;28(3):375-382.

6. Malhotra R, Chan A, Malhotra C, Østbye T. Prevalence, awareness, treatment and control of hypertension in the elderly population of Singapore. Hypertens Res. 2010;33(12):1223-1231.

7. Sehestedt T, Ibsen H, Jørgensen T. Awareness, treatment and control of hypertension in Denmark. The Inter 99 study. Blood Press. 2007;16(5): 312-319.

8. Kronborg CN, Hallas J, Jacobsen IA. Prevalence, awareness, and control of arterial hypertension in Denmark. J Am Soc Hypertens. 2009;3(1): 19-24. e2.

9. Paulsen MS, Sondergaard J, Reuther L, et al. Treatment of 5413 hypertensive patients: a cross-sectional study. Fam Pract. 2011;28(6): 599-607.

10. Yusuf S, Islam S, Chow CK, et al; Prospective Urban Rural Epidemiology (PURE) Study Investigators. Use of secondary prevention drugs for cardiovascular disease in the community in high-income, middleincome, and low-income countries (the PURE Study): a prospective epidemiological survey. Lancet. 2011;378(9798):1231-1243.

11. Neter JE, Stam BE, Kok FJ, Grobbee DE, Geleijnse JM. Influence of weight reduction on blood pressure: a meta-analysis of randomized controlled trials. Hypertension. 2003;42(5):878-884.

12. Romero R, Bonet J, de la Sierra A, Aguilera MT; Esopoh Study Investigators. Undiagnosed obesity in hypertension: clinical and therapeutic implications. Blood Press. 2007;16(6):347-353.

13. He FJ, Li J, Macgregor GA. Effect of longer term modest salt reduction on blood pressure: Cochrane systematic review and meta-analysis of randomised trials. BMJ. 2013;346:f1325.

14. Taylor RS, Ashton KE, Moxham T, Hooper L, Ebrahim S. Reduced dietary salt for the prevention of cardiovascular disease: a meta-analysis of randomized controlled trials (Cochrane review). Am J Hypertens. 2011;24(8):843-853.

15. Rossi A, Dikareva A, Bacon SL, Daskalopoulou SS. The impact of physical activity on mortality in patients with high blood pressure: a systematic review. J Hypertens. 2012;30(7):1277-1288.

16. Vanhees L, Geladas N, Hansen D, et al. Importance of characteristics and modalities of physical activity and exercise in the management of cardiovascular health in individuals with cardiovascular risk factors: recommendations from the EACPR. Part II. Eur J Prev Cardiol. 2012;19(5):1005-1033.

17. Puddey IB, Beilin LJ, Vandongen R. Regular alcohol use raises blood pressure in treated hypertensive subjects. A randomised controlled trial. Lancet. 1987;1(8534):647-651.

18. Akita S, Sacks FM, Svetkey LP, Conlin PR, Kimura G; DASH-Sodium Trial Collaborative Research Group. Effects of the Dietary Approaches to Stop Hypertension (DASH) diet on the pressure-natriuresis relationship. Hypertension. 2003;42(1):8-13.

19. Dickinson HO, Mason JM, Nicolson DJ, et al. Lifestyle interventions to reduce raised blood pressure: a systematic review of randomized controlled trials. J Hypertens. 2006;24(2):215-233.

20. Stamler J, Caggiula AW, Grandits GA. Relation of body mass and alcohol, nutrient, fiber, and caffeine intakes to blood pressure in the special intervention and usual care groups in the Multiple Risk Factor Intervention Trial. Am J Clin Nutr. 1997;65(Suppl 1):338S-365S.

21. Munck A. Hypertension I Almen Praksis - Patientspørgeskema. [Hypertension in General Practice - Patient Questionnaire]. Odense: Audit Projekt Odense; 2008. Available from: http://www.apo-danmark. dk/files/pub/1833.pdf. Accessed August 28, 2013.

22. Kearney PM, Whelton M, Reynolds K, Whelton PK, He J. Worldwide prevalence of hypertension: a systematic review. J Hypertens. 2004;22(1):11-19.

23. Mancia G, Fagard R, Narkiewicz K, et al; Task Force Members. 2013 ESH/ESC Guidelines for the management of arterial hypertension: the Task Force for the management of arterial hypertension of the European Society of Hypertension (ESH) and of the European Society of Cardiology (ESC). J Hypertens. 2013;31(7):1281-1357. 
24. Ong KL, Cheung BM, Man YB, Lau CP, Lam KS. Prevalence, awareness, treatment, and control of hypertension among United States adults 1999-2004. Hypertension. 2007;49(1):69-75.

25. Lee YS. Awareness of blood pressure among older adults: a cross-sectional descriptive study. Int J Nurs Stud. 2007;44(5): 796-804.

26. Petrella RJ, Campbell NR. Awareness and misconception of hypertension in Canada: results of a national survey. Can J Cardiol. 2005;21(7):589-593.

27. Steiner S, Dorner TE, Fodor JG, Kunze M, Rieder A. Blood pressure awareness in Austria: lessons from a 30 years horizon. Am J Hypertens. 2011;24(4):408-414.

28. Prugger C, Keil U, Wellmann J, et al; EUROASPIRE III Study Group. Blood pressure control and knowledge of target blood pressure in coronary patients across Europe: results from the EUROASPIRE III survey. J Hypertens. 2011;29(8):1641-1648.

29. Drivsholm T, Eplov LF, Davidsen M, et al. Representativeness in population-based studies: a detailed description of non-response in a Danish cohort study. Scand J Public Health. 2006;34(6):623-631.
30. Molenaar EA, Van Ameijden EJ, Grobbee DE, Numans ME. Comparison of routine care self-reported and biometrical data on hypertension and diabetes: results of the Utrecht Health Project. Eur J Public Health. 2007;17(2):199-205.

31. Oksanen T, Kivimäki M, Pentti J, Virtanen M, Klaukka T, Vahtera J. Self-report as an indicator of incident disease. Ann Epidemiol. 2010;20(7):547-554.

32. Cobiac LJ, Vos T, Veerman JL. Cost-effectiveness of interventions to reduce dietary salt intake. Heart. 2010;96(23):1920-1925.

33. Glynn LG, Murphy AW, Smith SM, Schroeder K, Fahey T. Interventions used to improve control of blood pressure in patients with hypertension [review]. Cochrane Database Syst Rev. 2010;3:CD005182.

34. Andersen UO, Jensen GB. Trends and determinant factors in hypertension control in a population study with 25 years of follow-up. J Hypertens. 2010;28(5):1091-1096.
Clinical Epidemiology

\section{Publish your work in this journal}

Clinical Epidemiology is an international, peer-reviewed, open access journal focusing on disease and drug epidemiology, identification of risk factors and screening procedures to develop optimal preventative initiatives and programs. Specific topics include: diagnosis, prognosis, treatment, screening, prevention, risk factor modification, systematic

Submit your manuscript here: http://www.dovepress.com/clinical-epidemiology-journa

\section{Dovepress}

reviews, risk \& safety of medical interventions, epidemiology \& biostatical methods, evaluation of guidelines, translational medicine, health policies \& economic evaluations. The manuscript management system is completely online and includes a very quick and fair peer-review system, which is all easy to use. 